\title{
Is subgroup analysis of intermediate-risk non-muscle invasive bladder cancer important in predicting recurrence?
}

\section{Orta riskli kas invaze olmayan mesane kanserinde, alt grup analizi rekürrens gelişimini öngörmede önemli midir?}

\author{
İsmail Selvi ${ }^{1}$ Erdem Öztürk ${ }^{2}$ \\ ${ }^{1}$ Karabük Üniversitesi Eğitim ve Araştırma Hastanesi, Üroloji Kliniği \\ ${ }^{2}$ Sağlık Bilimleri Üniversitesi Dr. Abdurrahman Yurtaslan Ankara Onkoloji Eğitim ve Araştırma Hastanesi, \\ Üroloji Kliniği
}

\section{ÖZET}

GíRiş ve AMAÇ: Oldukça heterojen bir grup sayılan orta riskli kas invaze olmayan mesane kanserlerinde (KİMK), tümör büyüklüğü, sayısı ve önceki rekürrens durumu açısından alt gruplar oluşturarak, hangi etkenin rekürrensi öngörmede daha önemli olduğunu değerlendirmeyi amaçladık.

YÖNTEM ve GEREÇLER: Kliniğimizde Ocak 2009-Aralık 2015 arasında, orta riskli KİMK tanısıyla tedavi ve takip edilen 99 hasta retrospektif olarak değerlendirildi. Primer, tek sayıda, Ta evre, düşük dereceli, $3 \mathrm{~cm}$ 'den büyük ( $>3 \mathrm{~cm}$ ) olan tümörler Grup I; Primer, Ta evre, düşük dereceli, $3 \mathrm{~cm}$ 'den küçük $(<3 \mathrm{~cm})$, multipl sayıda olan tümörler Grup II; daha önce düşük risk grubunda olan ve takiplerinde tek sayıda, $<3 \mathrm{~cm}$, düşük dereceli tümür rekürrensi olanlar Grup III olarak sinıflandırıldı. Üç grup klinik, patolojik bulgular ve takipte rekürrens gelişimi açısından karşılaştırıldı.

BULGULAR: Hastaların ortalama yaş1 $65.73 \pm 12.21$ olup, ortanca 48 (15-84) aylık takipte toplamda 41 (\%41.4) hastada rekürrens görülmüştür. Grup III'te gözlenen rekürrens oranı (\%58.8), Grup I (\%29.6) ve Grup II'den (\%34.2) anlamlı olarak daha yüksek bulundu ( $\mathrm{p}=0.039)$. Grup III’teki hastaların öngörülen rekürrenssiz sağkalım süresi (36.1 ay), Grup I (54.8 ay) ve Grup II'deki hastalardan (61.2 ay) anlamlı olarak daha düşük izlendi (sırasıyla $\mathrm{p}=0.01$ ve $\mathrm{p}=0.003$ ). Tek değişkenli analizde önceki rekürrens varlığı, tümör boyutu, sayısı ve CUETO skoru rekürrensi öngören bağımsız prediktif faktörler olarak belirtilirken; çok değişkenli analizde sadece önceki rekürrens varlığının daha önemli olarak bulundu.

TARTIŞMA ve SONUÇ: Orta riskli KIOMK olgularının alt gruplara ayrılarak daha benzer özellikte olanların sinıflandırılması, tümör tedavisi ve takibini belirlemede yol gösterici olabilmektedir. Önceden rekürrens öyküsü olan orta riskli hastalarda, yeni tümör rekürrenslerinin daha fazla olabileceğini düşünmekteyiz.

Anahtar Kelimeler: CUETO skoru, EORTC skoru, kas invaze olmayan mesane kanseri, orta risk, rekürrens

\begin{abstract}
INTRODUCTION: We aimed to create subgroups in terms of tumor size, number and previous recurrence status in intermediate-risk non-muscle invasive bladder cancer (NMIBC) and evaluate the predictive roles of these parameters in determining recurrence.

MATERIAL and METHODS: 99 patients who were treated and followed up between January 2009 and December 2015 with the diagnosis of intermediate-risk NMIBC were retrospectively analyzed. Group I consisted of primary, single, Ta grade, low grade, larger than $3 \mathrm{~cm}(>3 \mathrm{~cm})$ tumors; Group II consisted of primary, Ta grade, low grade, smaller than $3 \mathrm{~cm}(<3 \mathrm{~cm})$, multiple tumors and Group III consisted of recurrence of previous low-risk tumors. Three groups were compared in terms of clinical, pathological findings and recurrence in follow-up.

RESULTS: Mean age of patients was $65.73 \pm 12.21$. Among them, $41(41.4 \%)$ patients had recurrence in median 48 (15-84) monthly follow-up. Recurrence rate in Group III (58.8\%) was significantly higher than Group I $(29.6 \%)$ and Group II $(34.2 \%)(\mathrm{p}=0.039)$. The predicted recurrence-free survival (36.1 months) in Group III was significantly lower than Group I (54.8 months) and Group II (61.2 months) ( $\mathrm{p}=0.01$ and $\mathrm{p}=0.003$, respectively). In univariate analysis, the presence of previous recurrence, tumor size, number and CUETO score
\end{abstract}


were reported as independent predictive factors for recurrence. In multivariate analysis, only the presence of previous recurrence was found to be significant.

DISCUSSION and CONCLUSION: The subgroup analysis of intermediate-risk NMIBC may be helpful in determining tumor treatment and follow-up protocols. We state that new tumor recurrences may be higher in intermediate-risk NMIBC with previous recurrence history.

Keywords: CUETO score, EORTC score, intermediate risk, non-muscle invasive bladder cancer, recurrence

\section{GİRIŞ}

Mesane tümörleri dünya genelinde erkeklerde yedinci, kadınlarda ondördüncü sıklıkta görülmektedir (1). Mesane tümörlerinin tanı anında yaklaşı \% $\%$ 'i mesane mukozasına (Ta, karsinoma in situ) veya submukozasina (T1) sinırlıdır. Tümör karakteristikleri ve prognoz açısından oldukça heterojen olan bu tümörler, kas invaze olmayan mesane kanserleri (KİOMK) başlı̆̆ $\quad$ altında sınıflandırılmıştır (2).

KİOMK' nin düşük, orta ve yüksek riskli olarak üç gruba ayrılması, hastalık prognozunu öngörmek ve uygun adjuvan tedaviyi planlama açısından önemlidir. $\mathrm{Bu}$ amaçla yaygın olarak kullanılan sinıflama sistemi, European Organization for Research and Treatment of Cancer (EORTC)' nin belirlediği gruplamadır (3). Buna göre, primer, tek, $3 \mathrm{~cm}$ 'den küçük $(<3 \mathrm{~cm})$, Ta evre, düşük dereceli ve karsinoma in situ'nun eşlik etmediği tümörler düşük riskli grubu oluşturur. Yüksek riskli grupta ise, T1 evre, yüksek dereceli, karsinoma in situ'nun eşlik ettiği tümörler yer alır. Ayrıca çok sayıda, 3 cm' den büyük $(>3 \mathrm{~cm})$, tekrarlayan, Ta evre, düşük dereceli tümör özelliklerinin hepsini taşıyan olgular da bu gruba dahil edilmiştir.

Düşük ve yüksek risk gruplarına dahil edilemeyen özellikteki tümörler ise orta riskli grupta yer almaktadır. $\mathrm{Bu}$ nedenle orta risk grubunda yer alan tümörler daha heterojendir ve patolojik özelliklerinin, diğer iki grup kadar iyi tanımlanmadığı düşünülmektedir (4). Dahası başlangıçta yüksek riskli tümör saptanan hastalarda, adjuvan tedaviler sonrası izlemde düşük dereceli bir tümör nüksü saptandığında, hangi gruba dahil edilip tedavisinin düzenlenmesi gerektiği de netlik kazanamamıştır. Bu arada kalınan hastaların da çoğu kez orta riskli kabul edildiği görülmektedir $(5,6)$. Orta risk grubundaki tümörlerde adjuvan tedavi stratejileri de diğer iki risk grubu kadar netlik kazanamamıştır.

Çalışmamızda tümör büyüklüğü (>3 $\mathrm{cm})$, sayıs1 ve önceki rekürrens durumuna göre orta riskli tümörleri kendi içerisinde üç alt gruba ayırarak, prognoz açısından bu heterojen grupta daha doğru bir değerlendirme yapabilmeyi amaçladık.

\section{MATERYAL ve METOT}

Kliniğimizde Ocak 2009 - Aralık 2015 tarihleri arasında, mesane tümörü nedeniyle transüretral tümör rezeksiyonu (TUR-MT) yapılan, patolojik tanıs1 KİOMK gelen,verilerine tam olarak ulaşlabilen 275 hasta retrospektif olarak değerlendirildi. $\mathrm{Bu}$ hastalar EORTC sinıflamasına göre risk gruplarına ayrıldı. Hastaların 117' sinin düşük, 99'unun orta, 59'unun yüksek risk grubunda olduğu belirlendi. Orta risk grubundaki 99 hasta çalışmamıza dahil edildi. Çalışmamız, insan katılımcıları içeren çalışmalarda gerçekleştirilen tüm prosedürlerde olduğu gibi, kurumsal ve / veya ulusal araştırma komitesinin etik standartlarına, 1964 Helsinki beyanına ve daha sonraki değişikliklere, etik standartlara uygun olarak gerçekleştirilmiştir.

Hastaların demografik verileri, vücut kitle indeksi, tümör sayısı, büyüklüğü, önceki rekürrens varlığı, patolojik tümör evresi, derecesi, TUR-MT sonrası uygulanan adjuvan tedavi tipi, takip süresi, takipte nüks gelişme durumu kaydedildi. Çalışmaya alınan 99 hasta üç gruba ayrıldı. Primer, tek sayıda, Ta evre, düşük dereceli, $>\mathbf{3} \mathbf{~ c m}$ olan tümörler Grup I; Primer, Ta evre, düşük dereceli, $<3 \mathrm{~cm}$, 
multipl sayıda olan tümörler Grup II; daha önce düşük risk grubunda olan ve takiplerinde tek sayıda, $<3 \mathrm{~cm}$, düşük dereceli tümür rekürrensi olanlar Grup III olarak adlandırıldı.

Tüm hastalar için tümör sayısı, büyüklüğü, önceki rekürrens varlığı, patolojik tümör evresi ve derecesine ait veriler kullanılarak, EORTC tümör modeline göre rekürrens skoru hesaplandı (7). Benzer şekilde, Spanish Urological Club for Oncological Treatment (CUETO) skoru hastaların cinsiyet, yaş, önceki rekürrens varlığı, tümör sayısı ve derecesi ile ilgili verileri kullanılarak hesaplandı (8). Üç grup onkolojik sonuçlar açısından karşılaştırıldı.

\section{İstatistiksel Analiz}

Kolmogorov-Smirnov ve Shapiro-Wilk testleri ile normalite durumu değerlendirildikten sonra, üç grup arasındaki farklılıkları karşılaştırırken, kategorik değişkenler için Pearson ki-kare analizi; sürekli değişkenler için tek yönlü varyans analizi (ANOVA) veya KruskalWallis testi kullanıldı. Çoklu karşılaştırmalar yapılırken Tukey testi uygulandi. Rekürrenssiz sağkalım analizi için Kaplan-Meier, buna etki eden değişkenleri belirlemede Cox regresyon analizi kullanıldı. Analizler IBM SPSS Statistics 21 (IBM, Armonk, NY USA) yazılımı kullanılarak yapıldı. $\mathrm{p}<0.05$ değerleri istatistiksel olarak anlamlı kabul edildi.

\section{BULGULAR}

Çalışmaya dahil edilen 99 hastanın ortalama yaş1 $65.73 \pm 12.21$ olup, hastaların 88 (\% 88.9)' i erkek, 11 (\% 11.1)' i kadındı. Ortanca 48 (1584) aylık takip süresi boyunca 41 (\% 41.4) hastada rekürrens gerçekleşmiştir. Hastalara ait demografik, klinik veriler ve onkolojik sonuçlar Tablo 1' de gösterilmiştir. Rekürrens olasıllğını değerlendirmek için kullanılan iki nomogram olan EORTC ve CUETO skorları incelendiğinde; EORTC skoru Grup II'de Grup III'e göre anlamlı olarak daha yüksek (3.47 \pm 1.10 vs. $2.53 \pm 0.89, \mathrm{p}<0.001)$ saptanırken, Grup I'de diğer iki gruba göre anlamlı farklılık bulunmadı. CUETO skoru açısından, üç grup arasında anlamlı fark gözlenirken $(\mathrm{p}<0.001)$, en yüksek değer Grup III’te $(5.38 \pm 1.30)$ gözlendi. EORTC nomogramından farklı olarak, CUETO nomogramına dahil edilen yaş $(p=0.965)$ ve cinsiyet $(p=0.753)$ açısından ise gruplar arasında anlamlı fark bulunmadı (Tablo 1).

Üç grup karşılaştırıldığında; Grup III' te görülen rekürrens oran1 (\% 58.8), Grup I (\%29.6) ve Grup II'de (\%34.2) görülen oranlardan anlamlı olarak daha yüksek bulundu ( $\mathrm{p}=0.039)$. (Tablo 1). Grup III'teki hastaların öngörülen rekürrenssiz sağkalım süresi (36.1 ay), Grup I (54.8 ay) ve Grup II'deki hastalardan (61.2 ay) anlamlı olarak daha düşük izlendi (sırasıyla $\mathrm{p}=0.01$ ve $\mathrm{p}=0.003$ ). Grup I ve Grup II' deki hastaların öngörülen rekürrenssiz sağkalım süresi arasında ise, anlamlı farklılık gözlenmemiştir $(\mathrm{p}=0.859)$ (Şekil 1).

Tek değişkenli analizde önceki rekürrens varlığ olması, multipl sayıda tümör olması ve CUETO skoru rekürrensi öngören bağımsız prediktif faktörler olarak gözlenirken; çok değişkenli analizde sadece önceki rekürrens varlığı anlamlı değişken olarak saptandı (Tablo 2).

\section{TARTIŞMA}

KIOMK oldukça farklı patolojik ve prognostik özellikteki tümörlerin toplandığ $\mathrm{Bu}$ farklı özellikteki hastalar arasında, kısa ve uzun dönem izlemde oluşabilecek rekürrens ve progresyon riskini ayr1 ayr1 belirleyebilmek amaciyla, EORTC ve Genito-Urinary Cancer Group (GUCG) tarafindan en anlamlı 6 klinik ve patolojik parametre belirlenerek bir skorlama sistemi ve risk tablosu oluşturulmuştur (7). Bu sinıflamada tümör 
boyutu, sayısı ve önceki rekürrens varlığ1, izlemde rekürrensi belirleyecek en önemli prognostik faktörler olarak belirlenmiştir. Ancak bu nomogram oluşturulurken çalışmaya dahil edilen hiçbir hastaya, sekonder TUR-MT veya idame $\mathrm{BCG}$ tedavisi uygulanmamıştır. $\mathrm{Bu}$ nedenle, yüksek riskli olup da idame BCG tedavisi almış hastalara, bu nomogramlara göre değerlendirme yapıldığında, rekürrens ve progresyon riski olduğundan daha yüksek çıkabileceğinden yanılgıya yol açabilir. $\mathrm{Bu}$ çelişkili durumu düzeltebilmek amacıyla geliştirilen CUETO nomogramına, BCG ile tedavi edilmiş hastalar dahil edilmiş, ayrıca yaş ve cinsiyet parametreleri de eklenmiştir (8).

EORTC skorlama sistemi, rekürrens ve progresyon riskine göre hastaları başarılı şekilde siniflandırsa da, daha önce BCG tedavisi almış hastalarda öngörü değeri azaldığından, riskleri olduğundan daha yüksek tahmin etmektedir (9). Bu nedenle, daha önce BCG tedavisi almış hastalarda CUETO nomogramının kullanılması önerilmektedir (10). Bu nomogramlar düşük ve yüksek risk grupları için ayırt edici olsa da, tanımlaması halen çok kesinlik kazanamamış olan orta risk grubu hastalar için tedavi ve takip sürecine yol gösterecek yeni bir alt sinıflandırmaya duyulan ihtiyaç devam etmektedir. Çalışmamızda tek değişkenli analiz sonuçlarına göre, daha önce BCG uygulanmamış orta risk hastalarda, rekürrens gelişimini öngörmede CUETO skoru EORTC skorundan daha başarılı bulundu.

Orta risk grubuna dahil edilen hastalarda, TUR-MT sonrası sadece izlem seçilebildiği gibi, adjuvan tedavi olarak 1 yıla kadar intravezikal kemoterapi veya BCG da uygulanabilmektedir. Hatta adjuvan intravezikal tedavide yalnız indüksiyon dozunu uygulamanın yeterli olup olmayacağı, idame dozuna geçilmesinin gerekli olup olmadığı konusunda da tartışmalar sürmektedir $(5,6)$. Bu durum bize, orta risk grubundaki hastaların da alt gruplara ayrilıp değerlendirilmesi gerektiğini göstermektedir. Literatüre baktığımızda, orta riskli tümörleri inceleyen çok fazla çalışma bulunmamaktadır. Çalışmamızda tümör büyüklüğü $(>3 \mathrm{~cm})$, sayısı ve önceki rekürrens varlığı açısından orta riskli tümörleri kendi içerisinde üç alt gruba ayırarak, prognoz açısından değerlendirmeyi amaçladık.

Orta riskli tümörleri inceleyen en güncel çalışmalardan birinde, Matsumoto ve ark. (11) hastaları primer, multipl, düşük dereceli tümörler; düşük dereceli tümör sonrası gelişen düşük dereceli nüksler; yüksek dereceli tümör sonrası gelişen düşük dereceli nüksler şeklinde üçe ayırdılar. Gruplar arasında progresyon açısından farklılık gözlenmezken, yüksek dereceli tümör sonrası nükslerde rekürrenssiz sağkalımın daha az olduğu bildirildi. Adjuvan uygulamada intravezikal kemoterapi veya BCG' nin tümör rekürrensini önleme açısından benzer etkinlikte olduğu gözlendi. Biz ise çalışmamızda, Ta evre, düşük dereceli, orta risk grubundaki olguları tümör büyüklüğü $(>3 \mathrm{~cm})$, sayısı ve daha önce düşük risk grubunda olup izlemde rekürrens gelişmesi açısından üç alt gruba ayırdık. Nüks oranını daha önceden rekürrens gelişenlerde daha fazla saptarken, nükse kadar geçen süreyi tümör boyutu $>3 \mathrm{~cm}$ olan alt grupta daha kısa olarak gözledik. İntravezikal kemoterapi veya BCG' nin tümör rekürrensini önleme açısıdan benzer etkinlikte olduğunu gözlerken, çalışmamıza dahil edilen hastalardan rekürrens öyküsü olan grupta daha fazla oranda BCG tercih edildiğini tespit ettik.

Matsumoto ve ark. (11) orta riskli olgularda nüks ve progresyon gelişim riskini, multipl tümör varlığında ve düşük dereceli tümör rekürrensi geçmişi olanlarda benzer saptad1. Biz ise, düşük dereceli rekürrens öyküsü olan grupta (\% 58.8) multipl tümörü olanlara (\% 34.2) göre daha fazla yeni nüks geliştiğini gözledik.

Yüksek dereceli tümörlerde izlemde gelişen düşük dereceli nükslerin orta risk grubuna dahil edilmesi konusunda halen tartışmalar bulunmaktadır (12). Çünkü bu olgularda gözlenen nüks oranı, önceden düşük 
dereceli tümör öyküsü olan hastalarda görülen nükslerden daha fazladır. Hatta bu olgularda tümör progresyonunun daha fazla yaşandiğı bilindiğinden, adjuvan tedavide BCG uygulanmas1 daha fazla önerilmektedir (13). $\mathrm{Bu}$ nedenle tartışmalı olan bu grubu çalışmamıza dahil etmedik. Çalışmamıza dahil edilen her hastaya endikasyon dahilinde reTUR-MT yapılmış olup, adjuvan tedavi uygulamalarının kılavuzlarda önerildiği şekilde ürolog tercihine göre yapıldığını görmekteyiz (13). Belirtilen durumlar, literatürde bu konuda bildirilmiş en kapsamlı yayın olan Matsumoto ve ark. (11)'nın çalışmasına göre mevcut çalışmamızın güçlü yanlarıdır.

Çalışmamızın retrospektif dizaynı, düşük hasta sayısı içermesi, bu nedenle randomizasyon oluşturulamaması, izlem sonuçlarının tek merkeze ait olması başlıca kısitlayıcı etkenlerdir.

Sonuç olarak, orta riskli KİOMK olgularının kendi içinde alt gruplara ayrılmasının, hasta takip ve tedavi protokollerinin belirlenmesinde hasta bazlı bireyselleștirilmiş yaklașıma imkan vereceği açıkça anlaşılmaktadır. Önceden rekürrens öyküsü olanlarda, yeni nüks gelişimi açısından riskin daha fazla olduğu görülmektedir. $\mathrm{Bu}$ riski öngörmede CUETO skorunun EORTC skoruna göre prediktif gücü daha fazla bulunmuştur. Çok merkezli, geniş hasta say1l, prospektif, randomize, daha uzun takip süreli çalışmalarla, bulgularımızın desteklenmesine ihtiyaç vardır.

Çıkar Çatışması: Yok

Tablo 1. Hastaların demografik, klinik verileri ve onkolojik sonuçları

\begin{tabular}{|c|c|c|c|c|c|}
\hline Parametreler & $\begin{array}{c}\text { Grup I } \\
(\mathbf{n}: 27) \\
\end{array}$ & $\begin{array}{c}\text { Grup II } \\
(\mathbf{n}: 38) \\
\end{array}$ & Grup III (n:34) & Toplam (n:99) & p değeri \\
\hline $\begin{array}{c}\text { Yaş } \\
(\text { ortalama } \pm \text { standart sapma) }\end{array}$ & $66.26 \pm 9.84$ & $65.58 \pm 11.26$ & $65.47 \pm 14.97$ & $65.73 \pm 12.21$ & $\dagger 0.965$ \\
\hline $\begin{array}{c}\text { Cinsiyet }(\mathrm{n}, \%) \\
\text { erkek } \\
\text { kadın }\end{array}$ & $\begin{array}{c}23(85.2) \\
4(14.8)\end{array}$ & $\begin{array}{c}34(89.5) \\
4(10.5)\end{array}$ & $\begin{array}{c}31(91.2) \\
3(8.8)\end{array}$ & $\begin{array}{l}88(88.9) \\
11(11.1)\end{array}$ & +0.753 \\
\hline $\begin{array}{c}\text { VKI }\left(\mathrm{kg} / \mathrm{m}^{2}\right) \\
\text { (median, 25.-75. persentil) }\end{array}$ & $26.4(23.6-27.8)^{a}$ & $24.1(22.6-24.9)^{b}$ & $24.3(23.1-27.5)^{\mathrm{ab}}$ & $24.4(23.5-27.1)$ & $\S 0.013 *$ \\
\hline $\begin{array}{c}\text { Adjuvan tedavi }(\mathrm{n}, \%) \\
\text { Yok } \\
\text { Mitomisin C } \\
\text { BCG }\end{array}$ & $\begin{array}{c}4(14.8) \\
17(63.0) \\
6(22.2)\end{array}$ & $\begin{array}{c}5(13.2) \\
31(81.6) \\
2(5.3)\end{array}$ & $\begin{array}{c}0(0.0) \\
5(14.7) \\
29(85.3)\end{array}$ & $\begin{aligned} & 9(9.1) \\
53 & (53.5) \\
37 & (37.4)\end{aligned}$ & $t<0.001 *$ \\
\hline $\begin{array}{l}\text { Takip süreleri (ay) } \\
\text { median (min-max) }\end{array}$ & $52(24-76)$ & $50(15-84)$ & $42(24-78)$ & $48(15-84)$ & $\S 0.878$ \\
\hline $\begin{array}{c}\text { EORTC skoru } \\
\text { (ortalama } \pm \text { standart sapma) }\end{array}$ & $3.00 \pm 0.00^{\mathrm{ab}}$ & $3.47 \pm 1.10^{\mathrm{a}}$ & $2.53 \pm 0.89^{b}$ & $3.02 \pm 0.94$ & $\dagger<0.001 *$ \\
\hline $\begin{array}{c}\text { CUETO skoru } \\
\text { (ortalama } \pm \text { standart sapma) }\end{array}$ & $1.37 \pm 1.14^{\mathrm{a}}$ & $2.61 \pm 1.53^{b}$ & $5.38 \pm 1.30^{\mathrm{c}}$ & $3.22 \pm 2.12$ & $\dagger<0.001 *$ \\
\hline Rekürrens oranı (n,\%) & $8(29.6)$ & $13(34.2)$ & $20(58.8)$ & $41(41.4)$ & $\div 0.039 *$ \\
\hline $\begin{array}{c}\text { Rekürrense kadar geçen } \\
\text { süre (ay) } \\
\text { median (min-max) }\end{array}$ & $13.5(6-24)^{\mathrm{a}}$ & $21(12-30)^{b}$ & $7.5(3-15)^{c}$ & $12(3-30)$ & $\S<0.001 *$ \\
\hline
\end{tabular}

VKI: Vücut kitle indeksi, EORTC: European Organization for Research and Treatment of Cancer,

CUETO: Spanish Urological Club for Oncological Treatment

a, b, c: İstatistiksel olarak anlamlı farklılık gösteren gruplar farklı harflerle gösterilmiştir.

Aynı harfle belirtilen gruplar arasında istatistiksel bir fark yoktur.

ab: Diğer iki gruptan istatistiksel olarak anlamlı fark taşımayan grup

$\dagger$ Anova † Ki-kare $\quad \S$ Kruskal-Wallis $\quad * \mathrm{p}<0,05$ (Gruplar arasında anlamlı fark var) 
Tablo 2. Orta riskli KİOMK hastalarında TUR-MT ve adjuvan tedaviler sonrası takipte rekürrens gelişimini öngören faktörler

\begin{tabular}{|c|c|c|c|c|c|c|c|c|}
\hline & \multicolumn{4}{|c|}{ Tek değişkenli model } & \multicolumn{4}{|c|}{ Çok değişkenli model } \\
\hline & \multirow{2}{*}{ HR } & \multicolumn{2}{|c|}{$\% 95 \mathrm{GA}$} & \multirow{2}{*}{$\mathrm{p}$} & \multirow{2}{*}{ HR } & \multicolumn{2}{|c|}{$\% 95 \mathrm{GA}$} & \multirow{2}{*}{$\mathrm{p}$} \\
\hline & & Alt & Üst & & & Alt & Üst & \\
\hline Önceki rekürrens varlığ1 & 3.395 & 2.115 & 5.449 & $<0.001 *$ & 3.395 & 2.115 & 5.449 & $<0.001 *$ \\
\hline $\begin{array}{c}\text { Tümör büyüklüğ̈̈ } \\
(>3 \mathrm{~cm})\end{array}$ & 1.753 & 0.809 & 3.795 & $0.045 *$ & & & & \\
\hline Tümör sayısı (multipl) & 0.652 & 0.372 & 1.141 & $0.034 *$ & & & & \\
\hline EORTC skoru & 1.116 & 0.828 & 1.505 & 0.470 & & & & \\
\hline CUETO skoru & 1.310 & 1.126 & 1.524 & $<0.001 *$ & & & & \\
\hline
\end{tabular}

$* \mathrm{p}<0.05$ (Gruplar arasında anlamlı fark vardır.)

Lojistic regresyon

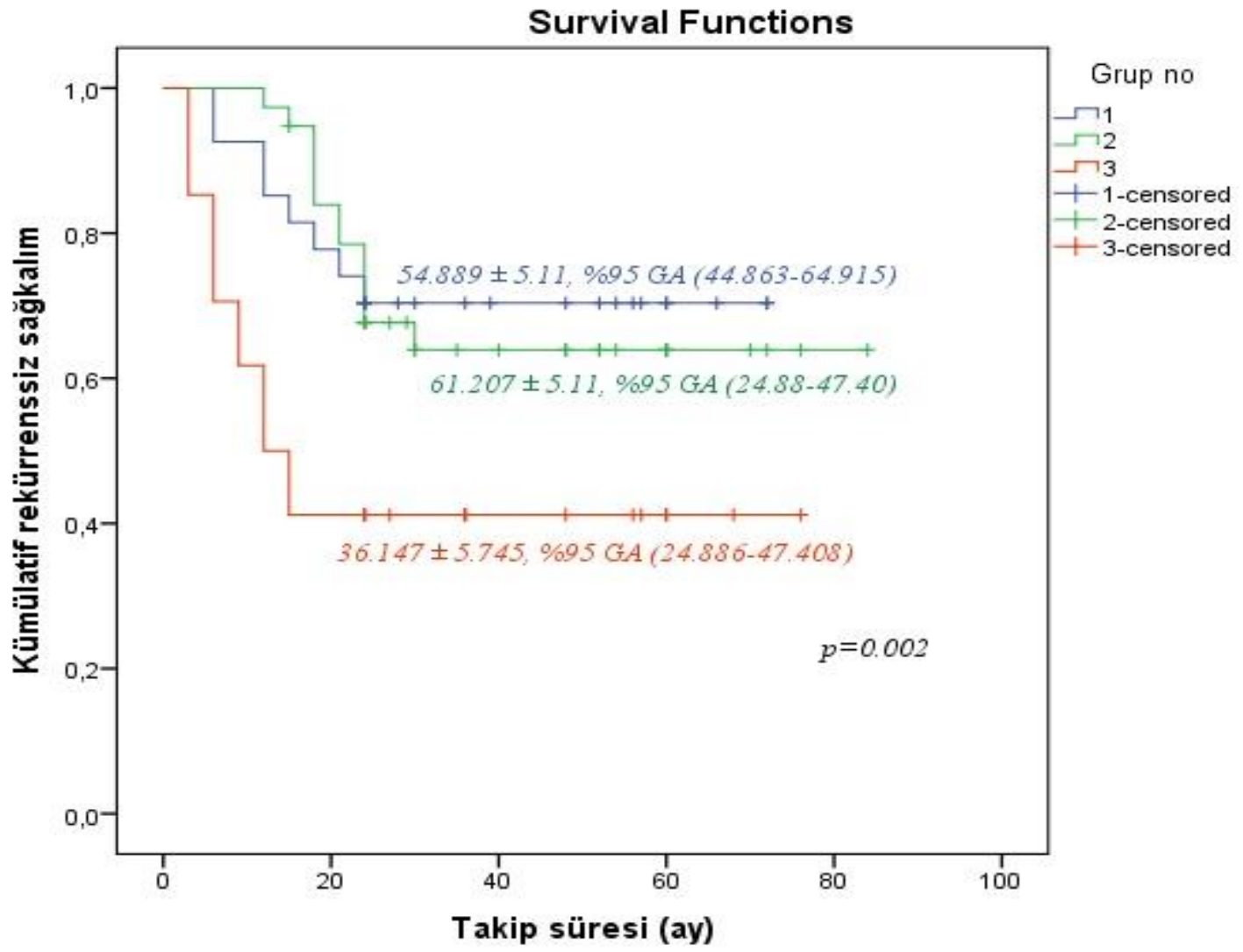

Şekil 1. Üç grup için öngörülen rekürrenssiz sağkalım süreleri 


\section{REFERANSLAR}

1. Ferlay J, Bray F, Forman D, et al. GLOBOCAN 2008 v1.2, Cancer Incidence and Mortality Worldwide:IARC CancerBase No. 10 2010, International Agency for Research on Cancer: Lyon, France.

2. Burger M, Catto JW, Dalbagni G, et al. Epidemiology and risk factors of urothelial bladder cancer. Eur Urol 2013;63:234-241.

3. Kuzgunbay B, Bayazit Y. The Risk Stratifications in Non-Muscle Invasive Bladder Cancer: How Much Accurate are the Methods That We Use? A Multi-Directional View. Bulletin of Urooncology 2015;14:18-22.

4. Kamat AM, Witjes JA, Brausi M, Soloway M, Lamm D, Persad R, et al. Defining and treating the spectrum of intermediate risk nonmuscle invasive bladder cancer.J Urol. 2014;192(2):305-15.

5. Chang SS, Boorjian SA, Chou R, et al. Diagnosis and treatment of non-muscle invasive bladder cancer: AUA/SUO guideline. Linthicum, Maryland: American Urological Association, 2016. Available at: https://www.auanet.org/education/guidelines/nonmuscle-invasive-bladder-cancer.cfm.

6. Babjuk M, Böhle A, Burger M, et al. Guidelines on non-muscle-invasive bladder cancer. Arnhem, The Netherlands: European Association of Urology, 2016; Available at: https://uroweb.org/guideline/non-muscle-invasivebladder-cancer/.

7. Sylvester RJ, vander Meijden AP, Oosterlinck W,et al. Predicting recurrence and progression in individual patients with stage TaT1 bladder cancer using EORTC risk tables:a combined analysis of
2596 patients from seven EORTC trials. Eur Urol 2006;49:466.

8. Fernandez-Gomez J, Madero R, Solsona E, et al.Predicting non-muscle invasive bladder cancer recurrence and progression in patients treated with bacillus Calmette-Guerin: the CUETO scoring model. J Urol 2009;182:2195.

9. Fernandez-Gomez J, Madero R, Solsona E, et al; Club Urológico Español de Tratamiento Oncológico. The EORTC tables overestimate the risk of recurrence and progression in patients with non-muscle invasive bladder cancer treated with bacillus Calmette-Guérin: external validation of the EORTC risk tables. Eur Urol 2011;60:423-430.

10. Babjuk $M$, Bohle A, Burger $M$, et al. EAU guidelines on Nonmuscle invasive bladder cancer (Ta, T1 and CIS). Edition presented at the EAU Annual Congress Stockholm 2014. ISBN:978-9079754-65-66.

11. Matsumoto K, Kikuchi E, Yanai $Y$, Hayakawa N, Ito $\mathrm{Y}$, Maeda $\mathrm{T}$, et al. Characterizing intermediaterisk non-muscle-invasive bladder cancer: Implications for the definition of intermediate risk and treatment strategy. Urol Oncol. 2017;35(5):208-214.

12. Simon $M$, Bosset $P O$, Rouanne $M$, Benhamou $S$, Radulescu C, Molinié V, et al. Multiple recurrences and risk of disease progression in patients with primary low-grade (TaG1) non-muscle-invasive bladder cancer and with low and intermediate EORTC-risk score. PLoS One. 2019;14(2):e0211721.

13. Woldu SL, Bagrodia A, Lotan Y. Guideline of guidelines: non-muscle-invasive bladder cancer.BJU Int. 2017;119(3):371-380. 